\title{
Myxopapillary ependymoma in a 6-year-old girl with paraplegia- timely intervention enabled complete recovery
}

\author{
N. Rajeshwari ${ }^{1}$, A. Savitha ${ }^{1 *}$, J. Prahada ${ }^{1}$, S. Rajkumar ${ }^{2}$, G. Nandini $^{3}$
}

\begin{abstract}
${ }^{1}$ Department of Pediatrics, Dr. Kamakshi Memorial Hospital, Pallikaranai, Chennai, Tamil Nadu, India ${ }^{2}$ Department of Neurosurgery, Dr. Kamakshi Memorial Hospital, Pallikaranai, Chennai, Tamil Nadu, India ${ }^{3}$ Department of Pathology, Dr. Kamakshi Memorial Hospital, Pallikaranai, Chennai, Tamil Nadu, India
\end{abstract}

Received: 18 June 2021

Revised: 26 June 2021

Accepted: 04 July 2021

\section{*Correspondence:}

Dr. A. Savitha,

E-mail: drsavitha_arun@yahoo.com

Copyright: (c) the author(s), publisher and licensee Medip Academy. This is an open-access article distributed under the terms of the Creative Commons Attribution Non-Commercial License, which permits unrestricted non-commercial use, distribution, and reproduction in any medium, provided the original work is properly cited.

\begin{abstract}
Intramedullary spinal cord tumors accounts for 4-10\% of all central nervous system tumors and 35-40\% of all intraspinal tumors in children. Biological behavior of these tumors is slow progression and often may not be recognized till they have attained significant size. Back pain, motor weakness, frequent falls and gait disturbances are the presenting complaints. Myxopapillary ependymoma is WHO grade 1 tumor associated with very good prognosis. Early diagnosis and complete surgical resection are the treatment of choice. We reported this case to emphasize the fact that appropriate diagnosis and complete surgical resection of the intraspinal tumor in a child with paraplegia with acute retention of urine with grade 0 power enabled complete neurological recovery.
\end{abstract}

Keywords: Intramedullary, Paraplegia, Myxopapillary ependymoma, Slow growing, Clear margins, Surgical resection

\section{INTRODUCTION}

Primary spine tumours are rare neoplasms that can lead to significant morbidity and mortality. Intramedullary spinal cord tumours are the rarest, and can lead severe neurological dysfunction add to significant impact on the quality of life.

Spine tumours are classified as extradural, intradural extramedullary and Intradural intramedullary. Due to the rarity of occurrence, these lesions are difficult to detect and often will lead to delay in the patient care. Pre-operative neurological status and tumour histology and the degree of tumour invasion dictate postoperative results. ${ }^{1}$

Myxopapillary ependymoma is a slow growing intramedullary spinal neoplasm. Early diagnosis and complete surgical resection of the myxopapillary ependymoma in a 6-year-old child with total paraplegia enabled complete recovery.

\section{CASE REPORT}

A 6-year-old girl who was apparently normal 1 month back presented to our paediatric emergency room with history of low back pain on and off for 1 month which started after mild tripping while playing. MRI pelvis done was normal. However, the child started to have severe abdominal pain on and off in the last 15 days. She also had difficulty in voiding urine associated with urgency and not able to void completely. During the last week she was unable to walk and also had burning sensations over the lower limbs and over the chest. They consulted a paediatrician found to have retention of urine and $600 \mathrm{ml}$ of urine was drained. As the abdominal pain, weakness and paraesthesia persisted, she was referred to our hospital for further evaluation. There was no history of fever, seizures, 
recent illness, trauma or recent vaccination. On examination her higher functions were normal, but she was extremely irritable and uncooperative as she had severe burning pain over lower limbs and chest. She had suprapubic tenderness and grade 0 power in the lower limbs deep tendon reflexes were absent in the lower limbs and bilateral plantar gave a withdrawal response. Upper limb neurological examination was normal. A provisional diagnosis of acute paraplegia with acute retention of urine was made. Blood counts were normal. MRI spine revealed heterogenous enhancement in the spinal cord D12-L3 level involving the conus and filum terminale suggestive of probable myxopapillary ependymoma with mild swelling in the lower thoracic region (secondary myelopathic changes) (Figure 1). MRS revealed a choline peak (Figure 2). MRI brain was normal. Neurologist and neurosurgical opinion were obtained. Treated with IV methylprednisolone pulse therapy. After explaining prognosis with high-risk consent, D12-L3 level laminectomy done, dura opened, midline myelectomy done and total excision of the tumour was done (Figure 3 and 4). Thorough haemostasis achieved and wound closed in layers. Post-operative period was uneventful and she remained stable. The child was discharged with continuous bladder catherization and regular physiotherapy. Biopsy revealed vascularised myxoid core which are radially surrounded by cuboidal to low columnar cells (Figure 5) with perivascular pseudo rosette (Figure 6) features of myxopapillary ependymoma grade 1. Regular physiotherapy was advised. The power improved gradually and bladder catheter was removed. She voided well and attained good bladder control gradually. At 3 months follow up, she was able to walk well and had good bowel and bladder control and there was no neurological deficit.

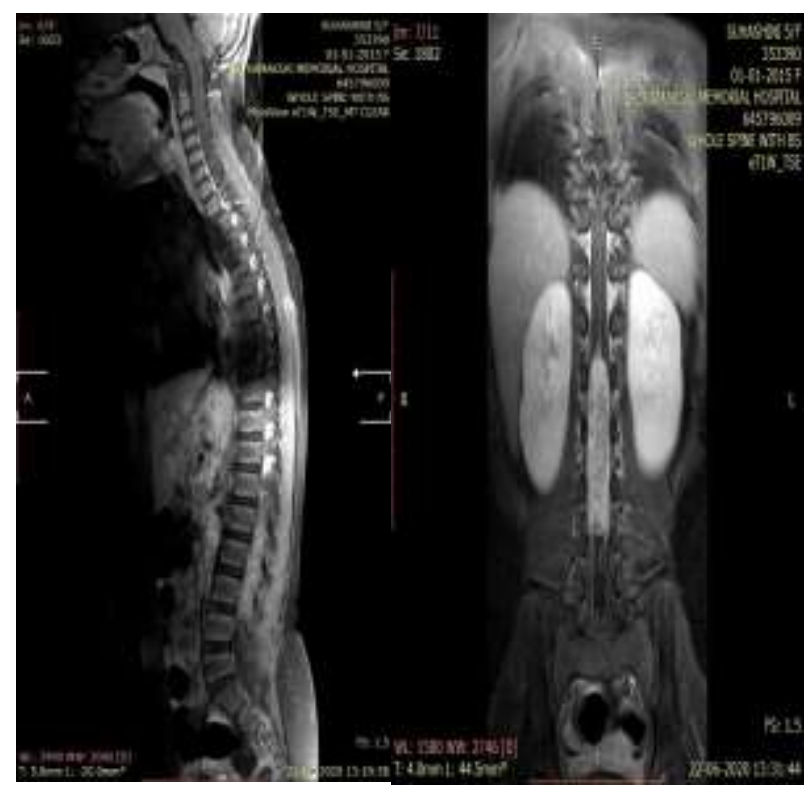

Figure 1: MRI spine- heterogenous enhancement in the spinal cord D12-L3 level involving the conus and filum terminal with mild swelling in the lower thoracic region.

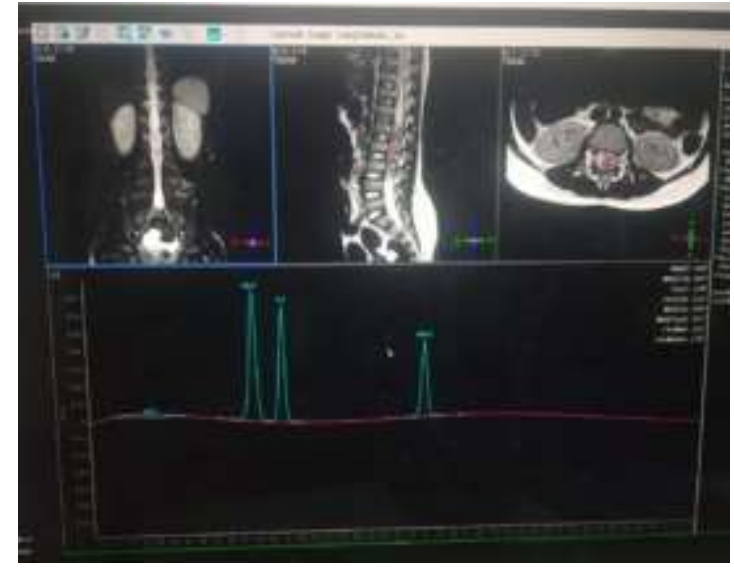

Figure 2: MRI spectroscopy showing a choline peak.

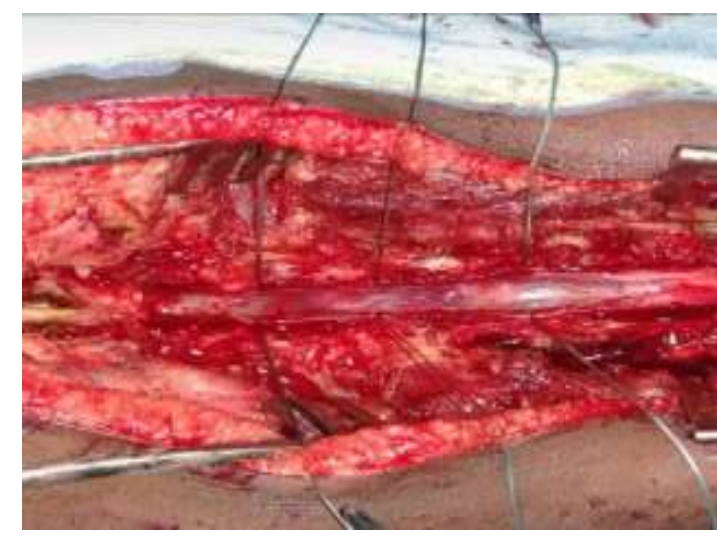

Figure 3: Per-operative finding, visualisation of tumour superficially.

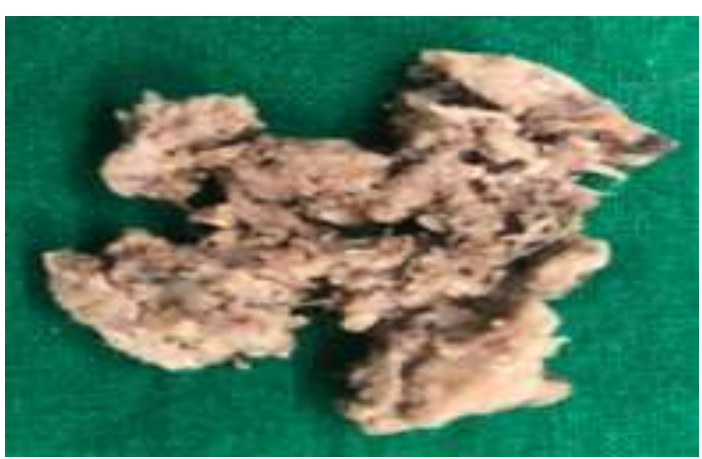

Figure 4: Gross section of tumour after resection.

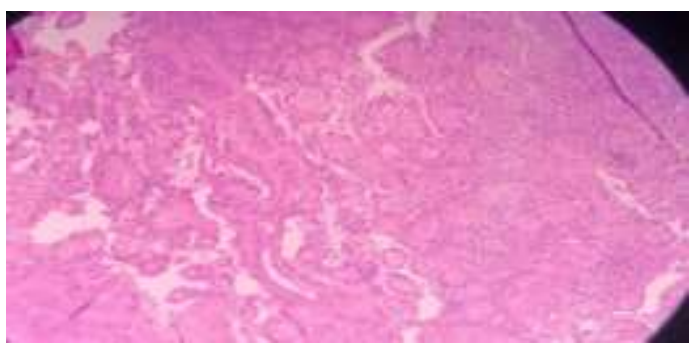

Figure 5: Vascularised myxoid with myxopapillary appearance surrounded by cuboid to low columnar cells. 


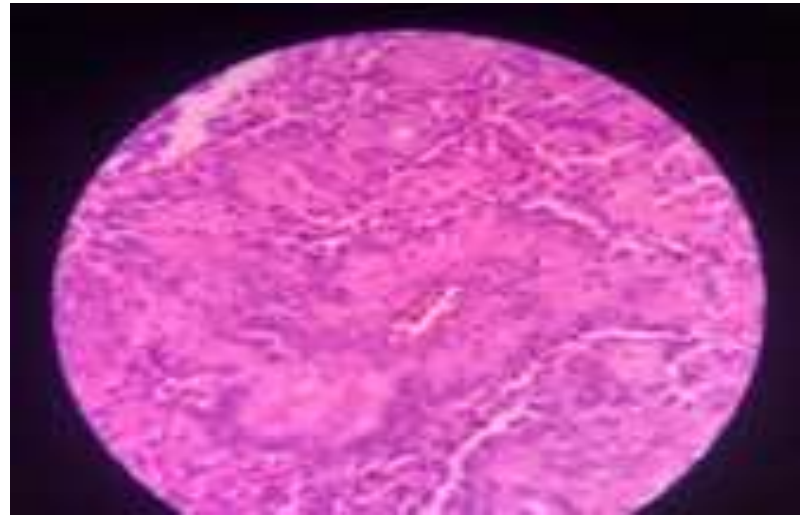

Figure 6: Perivascular pseudo rosettes.

\section{DISCUSSION}

Spinal cord neoplasms are more frequent towards the end of the first decade and the beginning of the second decade of life, although all age groups may be affected there is no gender predilection. ${ }^{2,4-6}$

Very young children tend to have more developmental types of tumours including teratomas, dermoid tumours, and epidermoid tumours predominantly in lumbosacral region whereas older children more commonly have astrocytomas found abundant in cervicothoracic region. ${ }^{7}$

Intramedullary spinal cord tumours arise within the substance of spinal cord itself and most of them are slow growing tumours. Approximately $10 \%$ of intramedullary spinal cord tumours are malignant astrocytomas but more are WHO grade $\mathrm{T} / \mathrm{II}$ tumours of glial or ependymal origin. ${ }^{8}$

Ependymomas and astrocytomas are the most common intramedullary tumours, accounting for more than $90 \% .^{2,8,9}$ Myxopapillary ependymomas encompass about $13 \%$ of all spinal ependymomas and $1-5 \%$ of all spinal neoplasms and are more common in male children and accounts for $90 \%$ of all tumours in the conus medullaris. It is benign and slow-growing neoplasm that has been histologically classified according to the WHO classification for ependymomas. (WHO grade 1). ${ }^{10}$

These tumours typically arise from the ependymal glia of the conus medullaris and filum terminale. These tumours are frequently polylobulated, fill the spinal canal, may scallop the adjacent vertebral bodies and can produce mucin. It has the predilection to the lumbosacral region. They present with lower back pain, leg weakness and sphincter dysfunction. Prognosis after complete resection is favourable. ${ }^{10,11}$

Extradural tumours (e.g., neurofibroma, sarcoma) accounts for almost half of the intraspinal tumours in childhood, spreading from nearby bone/intervertebral foramina. Intradural but extramedullary tumours occur in $1 / 4$ of patients, commonest being neurofibromas, dermoids, lipomata.
Pain is the most common clinical feature. Local pain along the spinal axis is frequent and is often described over the spinal segments overlying the tumour. Other symptoms include progressive motor weakness, progressive scoliosis, gait disturbance, and muscle rigidity with paraspinal muscle spasm. Sensory deficits are less common.

With the slow growing tumours, neuromuscular imbalance and growth may produce progressive musculoskeletal deformity such as head tilt, torticollis, kyphosis and scoliosis. $25-30 \%$ of children with a spinal cord tumour suffer from recurrent episodes of back pain. Hydrocephalus is reported in $15 \%$ of children with Intraspinal tumours. ${ }^{9,10}$ Most spinal cord tumours in children are diagnosed with significant delay. ${ }^{9,12}$

Children with back pain should be taken seriously, especially because back pain in healthy children without a history of recent trauma is very rare, often interpreted as growth pain.

Because of the complex development of the spinal cord and adjacent musculoskeletal structures, a tumour may be located significantly higher than the symptoms suggest. Consequently, if a spinal MRI is performed the entire spinal cord should be imaged.

A smaller percentage of children with spinal cord neoplasms may present with symptoms of increased intracranial pressure. It is important to perform a complete neurologic examination looking for central nervous system aetiology and perform imaging studies where appropriate. ${ }^{9,12}$

Magnetic resonance imaging is the study of choice to identify and delineate intramedullary spinal cord tumours. MR studies with IV contrast should be performed to identify the solid component, to show the cyst, edema and syrinx cavity if present. MRI of the brain may be necessary in children with hydrocephalus. Uniform enhancement, well defined margin, central location in the cord, syringohydromyelia and cap sign are characteristic MR features of ependymomas. The 'caps sign' is an imaging finding as a result of hemosiderin deposits caused by chronic haemorrhage. Multivariate analysis revealed that syringohydromelia was the significant factor distinguishing ependymomas from astrocytomas. Astrocytomas are characterised by large solid component, eccentric location, heterogenous enhancement pattern in MRI. Ependymomas usually present with a plane between the tumour and normal spinal cord tissue, and thus gross total resection is possible in many cases, in contrast to astrocytomas where the total resection is difficult because of the infiltrative nature of the lesions. ${ }^{12,13}$ Complete resection of myxopapillary ependymomas is associated with excellent long-term prognosis. ${ }^{10}$ Radiation therapy is likely warranted in cases of subtotal resection and recurrence of the intradural tumours, but is controversial in cases of total resection and extradural ependymomas. ${ }^{14}$ 


\section{CONCLUSION}

Proper diagnosis of intramedullary spinal cord tumours is of paramount importance. The manifestations of symptoms may be misleading. Myxopapillary ependymoma is a slow growing tumour, unlikely to metastasize and complete resection is associated with excellent long-term prognosis.

Funding: No funding sources

Conflict of interest: None declared

Ethical approval: Not required

\section{REFERENCES}

1. Samartzis D, Gillis CC, Shih P, Toole JE, Fessler RG. Intramedullary Spinal Cord Tumors: Part IEpidemiology, Pathophysiology, and Diagnosis. Global Spine J. 2015;5(5):425-35.

2. Koeller KK, Rosenblum RS, Morrison AL. Neoplasms of the spinal cord and filum terminale: radiologic-pathologic correlation. Radiographics. 2000;20(6):1721-49.

3. Kasim K, Thurnher MM, McKeever P, Sundgren PC. Intradural spinal tumors: current classification and MRI features. Neuroradiology. 2008;50(4):301-14.

4. Brotchi J, Dewitte O, Levivier M, Balériaux D, Vandesteene A, Raftopoulos C, Durand Jet al. A survey of 65 tumors within the spinal cord: surgical results and the importance of preoperative magnetic resonance imaging. Neurosurgery. 1991;29(5):6516.

5. Epstein F, Epstein N. Surgical treatment of spinal cord astrocytomas of childhood. A series of 19 patients. J Neurosurg. 1982;57(5):685-9.
6. Rossi A, Gandolfo C, Morana G, Tortori DP. Tumors of the spine in children. Neuroimaging Clin N Am. 2007;17(1):17-35.

7. Townsend N, Handler M, Fleitz J, Foreman N. Intramedullary spinal cord astrocytomas in children. Pediatr Blood Cancer. 2004; 43:629-32.

8. Wilson PE, Oleszek JL, Clayton GH. Pediatric spinal cord tumors and masses. J Spinal Cord Med. 2007;30(1):15-20.

9. Sun B, Wang C, Wang J, Liu A. MRI features of intramedullary spinal cord ependymomas. J Neuroimaging. 2003;13(4):346-51.

10. Sonneland PR, Scheithauer BW, Onofrio BM. Myxopapillary ependymoma. A clinicopathologic and immunocytochemical study of 77 cases. Cancer. 1985;56(4):883-93.

11. Allen JC, Siffert J, Hukin J. Clinical manifestations of childhood ependymoma: a multitude of syndromes. Pediatr Neurosurg. 1998;28(1):49-55.

12. Auguste KI, Gupta N. Pediatric intramedullary spinal cord tumors. Neurosurg Clin N Am. 2006;17(1):5161.

13. Kim DH, Kim JH, Choi SH, Sohn CH, Yun TJ, Kim $\mathrm{CH}$, et al. Differentiation between intramedullary spinal ependymoma and astrocytoma: comparative MRI analysis. Clin Radiol. 2014;69(1):29-35.

14. Bagley CA, Wilson S, Kothbaurer KF, Bookland MJ, Epstein F, Jallo GI. Long term outcomes following surgical resection of myxopapillary ependymomas. Neurosurg Rev. 2009;32(3):321-34.

Cite this article as: Rajeshwari N, Savitha A, Prahada J, Rajkumar S, Nandini G. Myxopapillary ependymoma in a 6-year-old girl with paraplegiatimely intervention enabled complete recovery. Int J Contemp Pediatr 2021;8:1431-4. 